\title{
Barriers to Care and 1-Year Mortality Among Newly Diagnosed HIV-Infected People in Durban, South Africa
}

\section{Citation}

Bassett, I. V., S. M. Coleman, J. Giddy, L. M. Bogart, C. E. Chaisson, D. Ross, M. J. E. Flash, et al. 2016. "Barriers to Care and 1-Year Mortality Among Newly Diagnosed HIV-Infected People in Durban, South Africa." Journal of Acquired Immune Deficiency Syndromes (1999) 74 (4): 432-438. doi:10.1097/QAI.0000000000001277. http://dx.doi.org/10.1097/QAI.0000000000001277.

\section{Published Version}

doi:10.1097/QAI.0000000000001277

\section{Permanent link}

http://nrs.harvard.edu/urn-3:HUL.InstRepos:32072225

\section{Terms of Use}

This article was downloaded from Harvard University's DASH repository, and is made available under the terms and conditions applicable to Other Posted Material, as set forth at http:// nrs.harvard.edu/urn-3:HUL.InstRepos:dash.current.terms-of-use\#LAA

\section{Share Your Story}

The Harvard community has made this article openly available.

Please share how this access benefits you. Submit a story.

Accessibility 


\title{
Barriers to Care and 1-Year Mortality Among Newly Diagnosed HIV-Infected People in Durban, South Africa
}

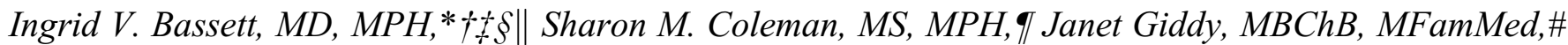 \\ Laura M. Bogart, PhD, $\$ \|^{* *+\dagger}$ Christine E. Chaisson, MPH, \ Douglas Ross, MBChB, MBA,tt \\ Moses J. E. Flash, BA, $\neq$ Tessa Govender, MSc,\# Rochelle P. Walensky, MD, MPH, $+\neq \S \| \S \xi$ \\ Kenneth A. Freedberg, MD, MSc, ${ }^{* \dagger} \$\|\|\|\| \mathbb{|}$ and Elena Losina, PhD $\$\|\| \| \# \# * * *$
}

\begin{abstract}
Background: Prompt entry into HIV care is often hindered by personal and structural barriers. Our objective was to evaluate the impact of self-perceived barriers to health care on 1-year mortality among newly diagnosed HIV-infected individuals in Durban, South Africa.
\end{abstract}

Methods: Before HIV testing at 4 outpatient sites, adults ( $\geq 18$ years) were surveyed regarding perceived barriers to care including (1) service delivery, (2) financial, (3) personal health perception, (4) logistical, and (5) structural. We assessed deaths via phone calls and the South African National Population Register. We used multivariable Cox proportional hazards models

Received for publication September 20, 2016; accepted November 21, 2016. From the *Division of Infectious Diseases, Massachusetts General Hospital, Boston, MA; †Division of General Internal Medicine, Massachusetts General Hospital, Boston, MA; †Medical Practice Evaluation Center, Massachusetts General Hospital, Boston, MA; §Harvard Medical School, Boston, MA; |Harvard University Center for AIDS Research, Harvard University, Boston, MA; $\uparrow$ Data Coordinating Center, Boston University School of Public Health, Boston, MA; \#McCord Hospital, Durban, South Africa; **Division of General Pediatrics, Department of Medicine, Boston Children's Hospital, Boston, MA; ††RAND Corporation, Santa Monica,

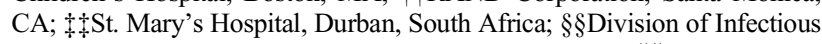
Diseases, Brigham and Women's Hospital, Boston, MA; ||||Department of Epidemiology, Boston University School of Public Health, Boston, MA; qqDepartment of Health Policy and Management, Harvard T.H. Chan School of Public Health, Boston, MA; \#\#Department of Orthopedic Surgery, Brigham and Women's Hospital, Boston, MA; and ***Department of Biostatistics, Boston University School of Public Health, Boston, MA.

The trial was funded by the US National Institute of Mental Health R01 MH090326 (I.V.B.) and R01 MH108427 (I.V.B.). This work was also supported by the Harvard University Center for AIDS Research P30 AI060354 (I.V.B.), the Steve and Deborah Gorlin MGH Research Scholar Award (R.P.W.), and the National Institutes of Health R01 AI058736 (K.A.F.) and R37 AI093269 (R.P.W.). The contents of this publication are solely the responsibility of the authors and do not necessarily represent the official views of the US National Institute of Mental Health

Presented in part at the 16th Conference on Retroviruses and Opportunistic Infections, February 22-25, 2016, Boston, MA.

The authors have no conflicts of interest to disclose.

Correspondence to: Ingrid V. Bassett, MD, MPH, 50 Staniford Street, 9th Floor, Boston, MA 02114 (e-mail: ibassett@partners.org).

Copyright (C) 2016 The Author(s). Published by Wolters Kluwer Health, Inc. This is an open-access article distributed under the terms of the Creative Commons Attribution-Non Commercial-No Derivatives License 4.0 (CCBY-NC-ND), where it is permissible to download and share the work provided it is properly cited. The work cannot be changed in any way or used commercially without permission from the journal. to determine the association between number of perceived barriers and death within 1 year.

Results: One thousand eight hundred ninety-nine HIV-infected participants enrolled. Median age was 33 years (interquartile range: $27-41$ years), $49 \%$ were females, and median CD4 count was $192 / \mu \mathrm{L}$ (interquartile range: $72-346 / \mu \mathrm{L}$ ). One thousand fifty-seven participants (56\%) reported no, 370 (20\%) reported $1-3$, and $460(24 \%)$ reported $>3$ barriers to care. By 1 year, 250 [13\%, 95\% confidence interval (CI): $12 \%$ to $15 \%$ ] participants died. Adjusting for age, sex, education, baseline CD4 count, distance to clinic, and tuberculosis status, participants with 1-3 barriers (adjusted hazard ratio: $1.49,95 \% \mathrm{CI}: 1.06$ to 2.08 ) and $>3$ barriers (adjusted hazard ratio: $1.81,95 \% \mathrm{CI}: 1.35$ to 2.43) had higher 1-year mortality risk compared with those without barriers.

Conclusions: HIV-infected individuals in South Africa who reported perceived barriers to medical care at diagnosis were more likely to die within 1 year. Targeted structural interventions, such as extended clinic hours, travel vouchers, and streamlined clinic operations, may improve linkage to care and antiretroviral therapy initiation for these people.

Key Words: mortality, barriers to care, HIV/TB coinfection, South Africa

(J Acquir Immune Defic Syndr 2017;74:432-438)

\section{INTRODUCTION}

People living with HIV (PLWH) in sub-Saharan Africa who consistently receive antiretroviral therapy (ART) can achieve a life expectancy similar to that of the general population. $^{1,2}$ South Africa is home to nearly 7 million PLWH, leading to more than 180,000 deaths annually. ${ }^{3}$ Despite having the largest ART program in the world, 58\% of South Africans with HIV are not on treatment. ${ }^{4}$ Those diagnosed with HIV but not yet on ART experience high mortality rates, as do those initiated on ART but who are inconsistently in care. ${ }^{4-9}$

We and others have documented high rates of loss to follow-up and mortality after HIV or tuberculosis (TB) diagnosis but before treatment initiation. ${ }^{5,10-17}$ Accurate ascertainment of mortality, particularly among those classified as lost to follow-up, is critical for evaluating the success 
of ART programs. Furthermore, studies evaluating risk of mortality in sub-Saharan Africa have only minimal clinical data assessing potential predictors of risk. ${ }^{8}$ However, contextual factors, poor emotional health, lack of social support, and competing needs at the time of diagnosis are likely to have an important effect on linkage to care and survival. ${ }^{18,19}$

PLWH in sub-Saharan Africa cite barriers to care, including low perceived need (because of not feeling sick enough to require treatment), structural factors (eg, transportation), and health system characteristics (eg, long wait times for care), as reasons for delaying ART initiation. ${ }^{18,19}$ Our objective was to evaluate whether self-identified barriers are independent predictors of mortality among newly diagnosed PLWH in Durban, South Africa. We hypothesized that these issues are integrally related to each other and that reporting self-perceived barriers to care at the time of HIV diagnosis would be an independent predictor of 1-year mortality.

\section{METHODS}

\section{Study Setting}

This study includes participants from the Sizanani Trial (NCT01188941), a randomized controlled trial that examined the efficacy of health system navigation and short messaging service-based reminders to attend appointments and to retrieve test results on linkage to and retention in HIV/TB care. Because the randomized intervention did not lead to a difference in linkage to HIV care, TB treatment completion, or death between the 2 study arms, we analyzed both groups together as a single cohort in the current study. The trial is described in further detail elsewhere. ${ }^{20,21}$ Briefly, participants were enrolled between August 11, 2010, and January 16, 2013, at 4 sites in the greater Durban area of South Africa: 2 outpatient departments at McCord and St. Mary's Hospitals and 2 primary health clinics. The McCord Hospital had a President's Emergency Plan for AIDS Relief (PEPFAR)-funded ART clinic, Sinikithemba, which closed on June 15, 2012, because of loss of PEPFAR funding; enrollment stopped at McCord's outpatient department on August 6, 2012.22 St. Mary's Hospital served a poorer peri-urban population $20 \mathrm{~km}$ west of Durban; it similarly had a PEPFAR-funded ART clinic. Participants were also enrolled at Tshelimnyama and Mariannhill, 2 nurse-driven municipal primary health clinics within the service area of St. Mary's Hospital. At the beginning of this study, these municipal clinics offered HIV testing and referral to St. Mary's Hospital for ART initiation. As a part of South Africa's decentralization of HIV care, starting October 1, 2011, these clinics began to offer ART and ongoing HIV care.

\section{Participants}

We enrolled English- or Zulu-speaking adults, 18 years or older, voluntarily presenting for HIV testing and not previously known to be living with HIV. We excluded children and pregnant women from the study because they entered HIV care through a separate system that had more active linkage to care procedures. The current analysis focuses on participants who were found to be HIV infected at enrollment. The study was approved by the McCord Hospital Medical Research Ethics Committee, St. Mary's Hospital Research Ethics Committee, University of KwaZuluNatal Biomedical Research Ethics Committee, and Partners Institutional Review Board (Protocol 2011-P-001195, Boston, MA).

A bilingual (Zulu/English) research assistant approached patients awaiting an HIV test to determine interest in and eligibility for the study. Eligible willing participants provided written informed consent in their preferred language. Consent was followed by a 15- to 20-minute baseline questionnaire to obtain detailed demographics and psychosocial information regarding their emotional health, social support, and self-perceived barriers to engaging in medical care, after which HIV testing was completed.

\section{Data Elements}

\section{Self-perceived Care Barriers}

The questionnaire included 12 questions regarding perceived barriers to care during the previous 6 months. ${ }^{23}$ We grouped these perceived care barriers into 5 categories that included (1) concerns about service delivery (eg, waiting too long to see a provider, not being treated with respect by clinic staff), (2) financial considerations (eg, inability to afford medication or transport), (3) personal health perception (eg, not being sick enough or being too sick), (4) logistical (eg, failure to get out of work, having care responsibilities for others), and (5) structural (eg, inability to access clinic because of clinic hours or transport, not knowing where to find care).

\section{Emotional Health and Social Support}

To gauge emotional health, we asked questions adapted from the 5-item Mental Health Inventory screening test and calculated a mental health composite (MHC) score. ${ }^{24}$ The questionnaire also contained 13 questions about availability of social support. These questions incorporated 4 social support scales (emotional/informational, tangible, positive interaction, and affectionate) used to calculate the Social Support Index (SSI) from the Medical Outcomes Study. ${ }^{25}$ The MHC and SSI scores were each averaged separately and converted into 2 separate scales from 0 to 100 , with higher numbers corresponding to better emotional health and social support. Based on the previous literature, ${ }^{26}$ we determined that an MHC $\leq 52$ indicated a positive depression screen and we defined an SSI below the study sample median to be a lack of social support. ${ }^{27}$

At the end of the questionnaire, participants provided their own contact information and that of a friend or family member for tracking purposes.

\section{Outcome Ascertainment}

Nine months post-enrollment, study staff members contacted the participants diagnosed with HIV at enrollment by phone for a brief interview. They also collected HIV test dates and results, CD4 counts, and the first 3 ART dispensing dates from electronic records and paper records at the study sites. We 
obtained vital status from clinical records, patients, and friends/ family members reached during follow-up phone calls. In addition, we verified mortality data within 12 months of enrollment using South African identification numbers through a crossmatch with the South African National Population Register, which encompasses $\sim 90 \%$ of all deaths nationwide. ${ }^{8}$

The primary endpoint was death. The observation time was defined as the time from study enrollment until 12 months following baseline study visit. Events were restricted to the deaths that occurred within 12 months after the participants' baseline study interview. Study participants who did not reach the primary endpoint by 12 months were censored.

\section{Analysis}

We used descriptive statistics to characterize the study sample. We built Cox proportional hazards models to examine the association between number of self-perceived barriers to care and time to death. Preliminary unadjusted models were fit independently for each independent variable before adjusted models. Hazard ratios (HR) and 95\% confidence intervals (CI) are reported for each model. Preliminary analyses showed that each individual barrier had similar impact on time to death [adjusted HR (aHR): 1.42-1.55]. Also, very few participants reported only a single barrier or a combination of specific barriers. Given the results of preliminary analyses, we built the final model considering a "number of self-perceived barriers to care" predictor (0 barriers, 1-3 barriers, $>3$ barriers from the "Self-perceived Care Barriers" listed above). The multivariable analysis adjusted for age, sex, CD4 count category, education, distance from clinic, and TB status at enrollment. Because the randomized intervention did not lead to a difference in linkage to HIV care, TB treatment completion, or death between the 2 study arms, we analyzed both groups together as a single cohort. ${ }^{21}$ We tested the proportional hazards assumption on the final adjusted model by creating a timedependent covariate. An interaction term between number of self-perceived barriers to care and a function of survival time was included in the model. The time-dependent covariate was not significant $(P=0.54)$ supporting the proportionality assumption. We used an alpha of 0.05 to define the threshold for statistical significance. Analyses were performed using SAS software (version 9.3; SAS Institute, Cary, NC).

\section{Role of the Funding Source}

The funding source had no impact on the design and implementation of the study or data interpretation. The Data Coordinating Center investigators (S.M.C. and C.E.C.) and lead biostatistician (E.L.) had full data access.

\section{RESULTS}

\section{Cohort Characteristics}

Among 6536 people screened for the study, 4954 (76\%) were eligible for enrollment and 4903 (99\%) were

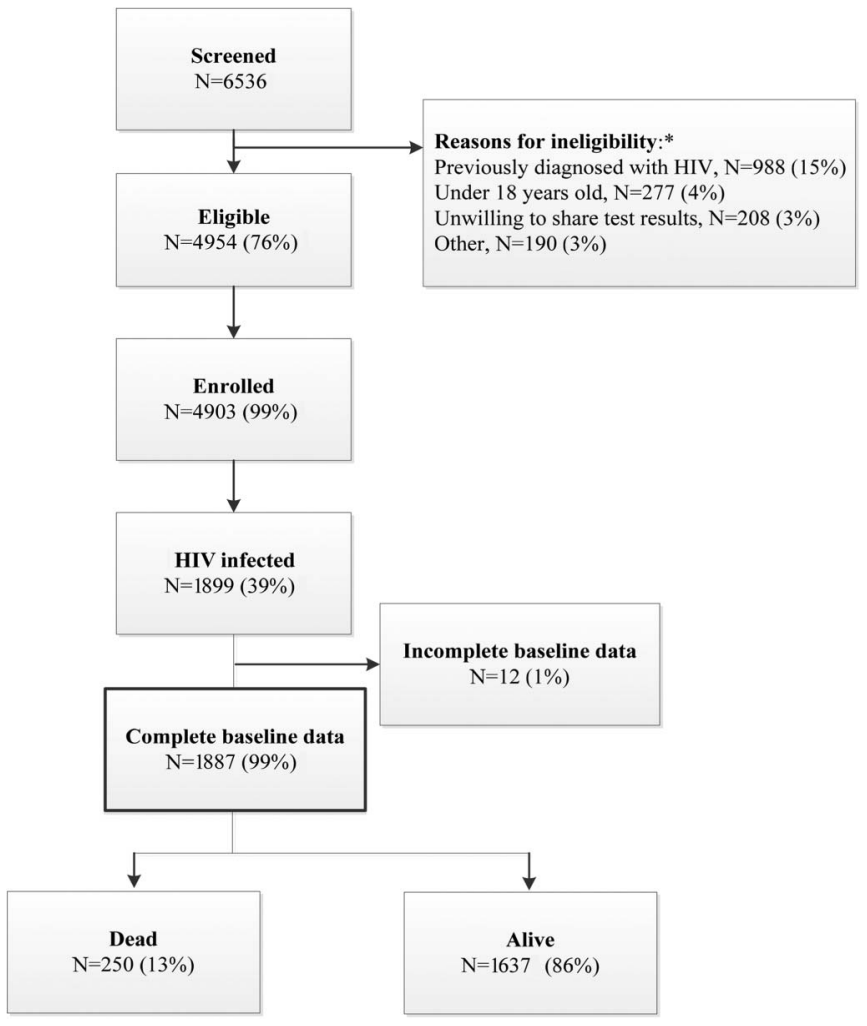

FIGURE 1. Participant flow. *Not mutually exclusive.

enrolled (Fig. 1). After enrollment, 1899 (39\%) of the participants were tested and newly diagnosed with HIV. One thousand eight hundred eighty-seven (99\%) of these participants had complete baseline survey data and were therefore included in this analysis. The median age was 33 years [interquartile range (IQR): 27-41 years], 928 (49\%) were females, and the median CD4 count was 192 cells $/ \mu \mathrm{L}$ (IQR: $72-346$ cells $/ \mu \mathrm{L})$ with $848(45 \%)$ presenting with CD4 $<200$ cells $/ \mu L$ (Table 1). Seven hundred seventy-four $(41 \%)$ of the participants had more than a high school education, 1533 (81\%) lived more than $5 \mathrm{~km}$ from a clinic, $253(13 \%)$ reported at least one hospital stay in the previous year, and $521(28 \%)$ had positive TB testing on the day of enrollment.

\section{Mortality}

By the end of the observation period, 250 (13\%, 95\% CI: $12 \%$ to $15 \%$ ) participants had died. Participants who died were older (median age 37 years, IQR: 30-46 years) compared with those alive at study conclusion (median age 33 years, IQR: $27-40$ years, $P<0.0001$ ) (Table 1 ). Those who had baseline CD4 count $<200$ cells/ $\mu \mathrm{L}$ had a higher risk of mortality than those with a baseline CD4 count $>350$ cells $/ \mu \mathrm{L}(22 \%$ versus $3 \%, P<0.0001)$. Risk of death was greater among men than women $(16 \%$ versus $10 \%, P=$ $0.0001)$, among those with less than a high school education compared with those with at least some high school education $(16 \%$ versus $9 \%, P<0.0001)$, among those 
TABLE 1. Cohort Characteristics of a Study of HIV Linkage to Care and Mortality in Durban, South Africa

\begin{tabular}{|c|c|c|c|c|}
\hline & $\begin{array}{c}\text { Overall, } \\
\mathbf{n}=\mathbf{1 8 8 7}\end{array}$ & $\begin{array}{c}\text { Dead at } \\
\text { Study } \\
\text { Conclusion, } \\
n=250\end{array}$ & $\begin{array}{c}\text { Alive at } \\
\text { Study } \\
\text { Conclusion, } \\
n=1637\end{array}$ & $\boldsymbol{P}$ \\
\hline \multicolumn{5}{|l|}{ Age, yrs } \\
\hline Median (IQR) & $33.0(27-41)$ & $37.0(30-46)$ & $33.0(27-40)$ & $<0.0001$ \\
\hline \multicolumn{5}{|l|}{ Sex, n $(\%)$} \\
\hline Male & $959(51)$ & $155(16)$ & $804(84)$ & 0.0001 \\
\hline Female & $928(49)$ & $95(10)$ & $833(90)$ & \\
\hline \multicolumn{5}{|l|}{$\begin{array}{l}\text { CD4 count, cells/ } \\
\mu \mathrm{L}, \mathrm{n}(\%)\end{array}$} \\
\hline $0-199$ & $848(45)$ & $187(22)$ & $661(78)$ & $<0.0001$ \\
\hline $200-350$ & $400(21)$ & $24(6)$ & $376(94)$ & \\
\hline$>350$ & $404(21)$ & $11(3)$ & $393(97)$ & \\
\hline \multicolumn{5}{|l|}{ Education, n (\%) } \\
\hline $\begin{array}{l}\text { Some high } \\
\text { school or } \\
\text { greater }\end{array}$ & $774(41)$ & $72(9)$ & $702(91)$ & $<0.0001$ \\
\hline $\begin{array}{l}\text { Primary school } \\
\text { or less }\end{array}$ & $1112(59)$ & $178(16)$ & $934(84)$ & \\
\hline \multicolumn{5}{|l|}{$\begin{array}{l}\text { Marital status, } \\
\text { n }(\%)\end{array}$} \\
\hline Never married & $1537(82)$ & $188(12)$ & $1349(88)$ & 0.0240 \\
\hline $\begin{array}{l}\text { Currently } \\
\text { married }\end{array}$ & 265 (14) & 47 (18) & $218(82)$ & \\
\hline $\begin{array}{l}\text { Divorce/ } \\
\text { separated/ } \\
\text { widowed }\end{array}$ & $85(5)$ & $15(18)$ & $70(82)$ & \\
\hline \multicolumn{5}{|l|}{$\begin{array}{l}\text { Distance from } \\
\text { clinic, } n(\%)\end{array}$} \\
\hline Less than $5 \mathrm{~km}$ & 354 (19) & $30(8)$ & $324(92)$ & 0.0033 \\
\hline At least $5 \mathrm{~km}$ & $1533(81)$ & $220(14)$ & $1313(86)$ & \\
\hline \multicolumn{5}{|l|}{$\begin{array}{l}\text { Randomization } \\
\text { group, n (\%) }\end{array}$} \\
\hline Standard of care & 927 (49) & $119(13)$ & $808(87)$ & 0.6044 \\
\hline Intervention & $960(51)$ & $131(14)$ & $829(86)$ & \\
\hline \multicolumn{5}{|l|}{$\begin{array}{l}\text { Hospital stays, } \\
\text { n (\%) }\end{array}$} \\
\hline 1 or more & $253(13)$ & $68(27)$ & $185(73)$ & $<0.0001$ \\
\hline None & $1634(87)$ & $182(11)$ & $1452(89)$ & \\
\hline \multicolumn{5}{|l|}{$\begin{array}{l}\text { Positive for } \mathrm{TB} \text { at } \\
\text { enrollment, } \\
\mathrm{n}(\%)\end{array}$} \\
\hline No & $1366(72)$ & $146(11)$ & $1220(89)$ & $<0.0001$ \\
\hline Yes & $521(28)$ & $104(20)$ & $417(80)$ & \\
\hline
\end{tabular}

living more than $5 \mathrm{~km}$ from the enrollment site compared with those living within $5 \mathrm{~km}$ of the site (14\% versus $8 \%$, $P=0.0033)$, and among those who had a hospital stay in the previous year compared with those who did not (27\% versus $11 \%, P<0.0001)$. Twenty percent of participants who had TB at enrollment died compared with $11 \%$ of those who did not have TB at enrollment $(P<0.0001)$. We did not find a statistically significant or clinically relevant relationship between emotional health or social support and mortality (Table 2). Those who reported $>3$ self-perceived barriers to care were twice as likely to die compared with those who reported 3 or fewer barriers to care $(22 \%$ versus $11 \%$, $P<0.0001)$.

\section{Self-Reported Barriers to Care, Mental Health, and Social Support at Enrollment}

With respect to the 5 self-perceived care barrier categories, $566(30 \%)$ reported service delivery barriers to care, 423 $(22 \%)$ reported financial barriers to care, 596 (32\%) reported personal health barriers to care, 334 (18\%) reported logistical barriers to care, and $540(29 \%)$ reported structural barriers to care (Table 2). Three hundred seventy participants $(20 \%)$ reported 1-3 self-perceived barriers to care and $460(24 \%)$ reported $>3$ barriers. Four hundred fifty $(24 \%)$ had a MHC score $\leq 52$, indicative of a positive depression screen, and $924(49 \%)$ had a social support score less than the median (Table 2).

TABLE 2. Emotional Health, Social Support, and Perceived Care Barriers at Baseline Among a Cohort of Newly Diagnosed HIV-Infected Participants in Durban, South Africa

\begin{tabular}{|c|c|c|c|c|}
\hline & $\begin{array}{l}\text { Overall, } \\
\mathrm{n}=1887\end{array}$ & $\begin{array}{c}\text { Dead at Study } \\
\text { Conclusion, } \\
\mathbf{n}=\mathbf{2 5 0}\end{array}$ & $\begin{array}{l}\text { Alive at Study } \\
\text { Conclusion, } \\
\text { n=1637 }\end{array}$ & $P$ \\
\hline \multicolumn{5}{|c|}{$\mathrm{MHI} \leq 52, \mathrm{n}(\%)$} \\
\hline No & $1437(76)$ & $181(13)$ & $1256(87)$ & 0.1349 \\
\hline Yes & $450(24)$ & $69(15)$ & $381(85)$ & \\
\hline \multicolumn{5}{|l|}{$\begin{array}{l}\text { SSI }<\text { Median } \\
(67), \text { n }(\%)\end{array}$} \\
\hline No & $963(51)$ & $126(13)$ & 837 (87) & 0.8297 \\
\hline Yes & 924 (49) & $124(13)$ & $800(87)$ & \\
\hline \multicolumn{5}{|c|}{$\begin{array}{l}\text { Service delivery } \\
\text { barriers, } \mathrm{n}(\%)\end{array}$} \\
\hline No & $1321(70)$ & $139(11)$ & $1182(89)$ & $<0.0001$ \\
\hline Yes & $566(30)$ & $111(20)$ & $455(80)$ & \\
\hline \multicolumn{5}{|c|}{$\begin{array}{l}\text { Financial } \\
\quad \text { barriers, n (\%) }\end{array}$} \\
\hline No & $1464(78)$ & 159 (11) & $1305(89)$ & $<0.0001$ \\
\hline Yes & $423(22)$ & $91(22)$ & $332(78)$ & \\
\hline \multicolumn{5}{|c|}{$\begin{array}{l}\text { Personal health } \\
\text { barriers, } \mathrm{n}(\%)\end{array}$} \\
\hline No & $1291(68)$ & $136(11)$ & $1155(89)$ & $<0.0001$ \\
\hline Yes & $596(32)$ & 114 (19) & $482(81)$ & \\
\hline \multicolumn{5}{|c|}{$\begin{array}{l}\text { Logistical } \\
\quad \text { barriers, n (\%) }\end{array}$} \\
\hline No & $1553(82)$ & $184(12)$ & $1369(88)$ & 0.0001 \\
\hline Yes & 334 (18) & $66(20)$ & $268(80)$ & \\
\hline \multicolumn{5}{|c|}{$\begin{array}{l}\text { Structural } \\
\quad \text { barriers, n (\%) }\end{array}$} \\
\hline No & $1347(71)$ & $143(11)$ & 1204 (89) & $<0.0001$ \\
\hline Yes & $540(29)$ & $107(20)$ & $433(80)$ & \\
\hline \multicolumn{5}{|c|}{$\begin{array}{l}\text { No. perceived } \\
\quad \text { barriers, } \mathrm{n}(\%)\end{array}$} \\
\hline No barriers & $1057(56)$ & $97(9)$ & $960(91)$ & $<0.0001$ \\
\hline 1-3 barriers & $370(20)$ & $54(15)$ & $316(85)$ & \\
\hline $\begin{array}{c}\text { More than } 3 \\
\text { barriers }\end{array}$ & $460(24)$ & $99(22)$ & $361(78)$ & \\
\hline
\end{tabular}

MHI, Mental Health Inventory; SSI, Social Support Index. 


\begin{tabular}{|c|c|c|c|c|}
\hline & Unadjusted HR $(95 \% \mathrm{CI})$ & $P$ & aHR $(95 \%$ CI) & $P$ \\
\hline \multicolumn{5}{|l|}{ No. perceived barriers } \\
\hline $1-3$ barriers & $1.68(1.20$ to 2.34$)$ & 0.003 & 1.49 (1.06 to 2.08$)$ & 0.020 \\
\hline More than 3 barriers & 2.54 (1.92 to 3.37$)$ & $<0.001$ & $1.81(1.35$ to 2.43$)$ & $<0.001$ \\
\hline Age at enrollment & & & $1.02(1.01$ to 1.04$)$ & $<0.001$ \\
\hline$>350$ cells $/ \mu \mathrm{L}$ & & & 1.00 & \\
\hline $200-350$ cells $/ \mu \mathrm{L}$ & & & $1.99(0.97$ to 4.11$)$ & 0.060 \\
\hline $0-199$ cells $/ \mu \mathrm{L}$ & & & 7.13 (3.85 to 13.19$)$ & $<0.001$ \\
\hline$<$ High school education & & & $1.31(0.98$ to 1.76$)$ & 0.070 \\
\hline$\geq 5 \mathrm{~km}$ from clinic & & & $1.37(0.92$ to 2.04$)$ & 0.130 \\
\hline
\end{tabular}

\section{Predictors of Mortality: Results From Multivariable Analyses}

We found that participants who identified 1-3 selfperceived barriers to care (aHR: $1.49,95 \% \mathrm{CI}: 1.06$ to 2.08 ) and $>3$ barriers (aHR: $1.81,95 \%$ CI: 1.35 to 2.43 ) had higher risk of 1-year mortality compared with those with no selfidentified barriers (Table 3).

\section{DISCUSSION}

Among 1887 PLWH enrolled in outpatient departments in Durban, South Africa, 250 (13\%) died within 1 year of enrollment. Self-reported barriers to health care were common, with $44 \%$ of the participants reporting at least one barrier to care and $24 \%$ reporting more than 3 barriers to care. These selfreported barriers were strong independent predictors of mortality, with a higher number of reported barriers correlating with a greater risk of mortality. After adjusting for demographic factors (ie, age, sex, and education) and clinical factors (ie, CD4 count and TB status at enrollment) known to be associated with mortality in PLWH, ${ }^{28,29}$ participants who reported more than 3 barriers were nearly twice as likely to die within 1 year of diagnosis compared with those who reported no barriers. Screening for barriers is a distinctive and novel method for identifying mortality risk when combined with additional clinical tests, such as CD4 count and concomitant TB screening.

Personal health barriers, service delivery barriers, and structural barriers were the most commonly perceived barriers to care. Many patients presented to HIV testing with incongruent perceptions of their health status, believing that they were too well or not well enough to receive care. Our results show that these incongruent perceptions can contribute to an increased risk of mortality. Other research has revealed that some patients, specifically those who feel healthy, perceive that ART initiation is linked with side effects and an overall decline in physical and mental health. ${ }^{30}$ As such, adequate counseling at the time of HIV testing and after diagnosis may improve linkage to care and ART initiation for these patients; for example, psychological counseling and adherence education were successful in improving TB treatment adherence. ${ }^{31}$ Furthermore, participants who felt that they were not treated with respect by clinic staff or that they had to wait too long to receive care were also at increased risk of death. Streamlined clinic operations and improvements in staff training and workload may help improve clinic operations and engagement in HIV care. ${ }^{32,33}$ Many participants found it difficult to seek out care, as they found clinic operating hours and transportation to be inconvenient. Travel vouchers and extended clinic operating hours could help link these patients to care. ${ }^{34,35}$ Although less frequently reported, a substantial number of participants reported financial barriers and logistical barriers (eg, inability to get days off from work or care responsibilities for others) to care. Travel vouchers and extended clinic operating hours may improve engagement in care for these participants.

A strength of our study was the ability to confirm vital status with the South African National Population Register. This allowed a comprehensive assessment of mortality, especially of those lost to follow-up during the study period. In sub-Saharan Africa, a substantial proportion of patients living with HIV are lost to follow-up during the process of linking to care and after ART initiation. ${ }^{36,37}$ Furthermore, patients who become lost to follow-up are at high risk of mortality compared with patients who remain in care. ${ }^{38,39}$ Therefore, studies with significant attrition in their patient population may be underestimating mortality; using the South African National Population Register, which accounts for $\sim 90 \%$ of deaths nationally, ${ }^{8}$ can mitigate this issue.

A potential explanation of higher mortality in patients who report barriers may be related to adherence to HIV care (ie, ART and follow-up appointments). Previous studies have established associations between suboptimal adherence and perceived poor service delivery, a lack of financial means for transport, patient perception that he or she is feeling well, responsibilities to care for dependents, and inconvenient clinic hours. ${ }^{30,40-45}$ Suboptimal adherence to HIV care is directly linked to poor virologic outcomes and mortality. ${ }^{46,47}$ Thus, it is possible that participants who reported barriers did not adhere to HIV care, as a mechanism leading to increased risk of death. Although we had previously found poor emotional health to be associated with late presentation with $\mathrm{HIV}$ and failure to obtain a CD4 count after diagnosis, ${ }^{27,48}$ we 
did not find an association between emotional health or social support and mortality in the current study. Although social support has been associated with reduced distress in PLWH, ${ }^{49}$ its impact on ART adherence has been mixed ${ }^{50-53}$; poor emotional health has more frequently been associated with nonadherence and accelerated disease progression, although not uniformly. ${ }^{54-56}$ Because barriers were identified before knowledge of HIV status, it is unclear how the new HIV diagnosis itself would affect specific self-identified barriers or whether the number of barriers is a proxy for another factor associated with higher mortality.

These findings should be taken in light of several limitations of the study. First, we did not have data related to opportunistic infections (other than TB) or noninfectious comorbidities that could be associated with mortality. It is possible that a higher prevalence of these comorbidities could have been present in participants who reported barriers to care. Second, we were unable to determine the cause of death for participants. Therefore, characterizing all these deaths as HIV related may lead to an overestimate of HIV-related death. However, regardless of the cause of death, it is likely that the barriers characterized in this study are barriers to obtaining any health care. As such, receiving clinical care and/or health monitoring would likely be beneficial in reducing mortality. Third, women comprised $49 \%$ of the cohort, less than in typical South African HIV cohorts. This may reflect that pregnant women were excluded from the study and that we enrolled participants before HIV testing. Fourth, we were unable to determine the proportion of those "in care" before death. Because outcomes were ascertained at study sites only, the proportion on ART in the parent study may have been an underestimate if participants sought care elsewhere. Finally, the instruments used to predict mortality in this study may not be readily transferable to routine clinical care. An important next step in this work will be to develop a short clinically practical screening instrument that can be used to stratify risk before HIV testing, as has been done with alcoholism (CAGE) and depression (PHQ-9, HADS, WBI-5, WHO-5, etc.). ${ }^{57-59}$

In conclusion, we found that newly diagnosed HIV patients' perceived barriers to care predict mortality risk within 1 year. Those reporting multiple perceived barriers to medical care at the time of diagnosis are nearly twice as likely to die within 1 year compared with those without barriers. Screening for barriers to care at HIV diagnosis can help identify patients for targeted interventions that may help link them to care and ART initiation, subsequently reducing their likelihood of death. Targeted structural interventions, such as extended clinic hours, travel vouchers, and more streamlined clinic operations, may improve outcomes for high-risk patients. The high prevalence of patients who report multiple barriers to care underlines the urgency for developing interventions that will alleviate these barriers and attenuate mortality.

\section{ACKNOWLEDGMENTS}

The authors would like to recognize the hard work and valuable contributions of the research staff. The authors thank the clinical sites for their dedication to research and gratefully acknowledge the study participants.

\section{REFERENCES}

1. Johnson LF, Mossong J, Dorrington RE, et al. Life expectancies of South African adults starting antiretroviral treatment: collaborative analysis of cohort studies. PLoS Med. 2013;10:e1001418.

2. Mills EJ, Bakanda C, Birungi J, et al. Life expectancy of persons receiving combination antiretroviral therapy in low-income countries: a cohort analysis from Uganda. Ann Intern Med. 2011;155:209-216.

3. UNAIDS. South Africa HIV and AIDS Estimates. 2015. Available at: http://www.unaids.org/en/regionscountries/countries/southafrica. Accessed August 31, 2016.

4. UNAIDS. The Gap Report. 2014. Available at: http://www.unaids.org/sites/ default/files/en/media/unaids/contentassets/documents/unaidspublication/2014/ UNAIDS_Gap_report_en.pdf. Accessed August 31, 2016.

5. Bassett IV, Chetty $\bar{S}$, Wang B, et al. Loss to follow-up and mortality among HIV-infected people co-infected with TB at ART initiation in Durban, South Africa. J Acquir Immune Defic Syndr. 2012;59:25-30.

6. Boulle A, Schomaker M, May MT, et al. Mortality in patients with HIV1 infection starting antiretroviral therapy in South Africa, Europe, or North America: a collaborative analysis of prospective studies. Plos Med. 2014;11:e1001718.

7. Braitstein P, Brinkhof MW, Dabis F, et al. Mortality of HIV-1-infected patients in the first year of antiretroviral therapy: comparison between low-income and high-income countries. Lancet. 2006;367:817-824.

8. Cornell M, Lessells R, Fox MP, et al. Mortality among adults transferred and lost to follow-up from antiretroviral therapy programmes in South Africa: a multicenter cohort study. J Acquir Immune Defic Syndr. 2014; 67:e67-e75.

9. Yiannoutsos CT, Johnson LF, Boulle A, et al. Estimated mortality of adult HIV-infected patients starting treatment with combination antiretroviral therapy. Sex Transm Infect. 2012;88(suppl 2):i33-i43.

10. Mugglin C, Estill J, Wandeler G, et al. Loss to programme between HIV diagnosis and initiation of antiretroviral therapy in sub-Saharan Africa: systematic review and meta-analysis. Trop Med Int Health. 2012;17: 1509-1520.

11. Kranzer K, Govindasamy D, Ford N, et al. Quantifying and addressing losses along the continuum of care for people living with HIV infection in sub-Saharan Africa: a systematic review. J Int AIDS Soc. 2012;15: 17383.

12. Cloete C, Regan S, Giddy J, et al. The linkage outcomes of a large-scale, rapid transfer of $\mathrm{HIV}$-infected patients from hospital-based to community-based clinics in South Africa. Open Forum Infect Dis. 2014;1:ofu058.

13. Bassett IV, Wang B, Chetty S, et al. Loss to care and death before antiretroviral therapy in Durban, South Africa. J Acquir Immune Defic Syndr. 2009;51:135-139.

14. Kranzer K, Zeinecker J, Ginsberg P, et al. Linkage to HIV care and antiretroviral therapy in Cape Town, South Africa. PLoS One. 2010;5: e13801.

15. Govindasamy D, van Schaik N, Kranzer K, et al. Linkage to HIV care from a mobile testing unit in South Africa by different CD4 count strata. J Acquir Immune Defic Syndr. 2011;58:344-352.

16. Bassett IV, Regan S, Luthuli P, et al. Linkage to care following community-based mobile HIV testing compared with clinic-based testing in Umlazi Township, Durban, South Africa. HIV Med. 2014;15:367-372.

17. MacPherson P, Houben RM, Glynn JR, et al. Pre-treatment loss to follow-up in tuberculosis patients in low- and lower-middle-income countries and high-burden countries: a systematic review and metaanalysis. Bull World Health Organ. 2014;92:126-138.

18. Layer EH, Kennedy CE, Beckham SW, et al. Multi-level factors affecting entry into and engagement in the HIV continuum of care in Iringa, Tanzania. PLoS One. 2014;9:e104961.

19. Musheke M, Bond V, Merten S. Deterrents to HIV-patient initiation of antiretroviral therapy in urban Lusaka, Zambia: a qualitative study. AIDS Patient Care STDS. 2013;27:231-241.

20. Bassett IV, Giddy J, Chaisson CE, et al. A randomized trial to optimize HIV/TB care in South Africa: design of the Sizanani trial. BMC Infect Dis. 2013;13:390. 
21. Bassett IV, Coleman SM, Giddy J, et al. Sizanani: a randomized trial of health system navigators to improve linkage to HIV and TB care in South Africa. J Acquir Immune Defic Syndr. 2016;73:154-160.

22. Katz IT, Bassett IV, Wright AA. PEPFAR in transition-implications for HIV care in South Africa. N Engl J Med. 2013;369:1385-1387.

23. Craw JA, Gardner LI, Marks G, et al. Brief strengths-based case management promotes entry into HIV medical care: results of the antiretroviral treatment access study-II. J Acquir Immune Defic Syndr. 2008:47:597-606.

24. Hays RD, Sherbourne CD, Mazel RM. The RAND 36-item health survey 1.0. Health Econ. 1993;2:217-227.

25. Sherbourne CD, Stewart AL. The MOS social support survey. Social Sci Med. 1991;32:705-714

26. Holmes WC. A short, psychiatric, case-finding measure for HIV seropositive outpatients: performance characteristics of the 5-item mental health subscale of the SF-20 in a male, seropositive sample. Med Care. 1998;36:237-243.

27. Drain PK, Losina E, Parker G, et al. Risk factors for late-stage HIV disease presentation at initial HIV diagnosis in Durban, South Africa. PLoS One. 2013;8:e55305.

28. Egger M, May M, Chene G, et al. Prognosis of HIV-1-infected patients starting highly active antiretroviral therapy: a collaborative analysis of prospective studies. Lancet. 2002;360:119-129.

29. Mabunda TE, Ramalivhana NJ, Dambisya YM. Mortality associated with tuberculosis/HIV co-infection among patients on TB treatment in the Limpopo province, South Africa. Afr Health Sci. 2014;14:849-854.

30. Katz IT, Dietrich J, Tshabalala G, et al. Understanding treatment refusal among adults presenting for HIV-testing in Soweto, South Africa: a qualitative study. AIDS Behav. 2015;19:704-714.

31. Tola HH, Shojaeizadeh D, Tol A, et al. Psychological and educational intervention to improve tuberculosis treatment adherence in Ethiopia based on health belief model: a cluster randomized control trial. PLoS One. 2016;11:e 0155147.

32. Rosen S, Maskew M, Fox MP, et al. Initiating antiretroviral therapy for HIV at a patient's first clinic visit: the RapIT randomized controlled trial. PLoS Med. 2016;13:e1002015.

33. Shet A, DeCosta A, Heylen E, et al. High rates of adherence and treatment success in a public and public-private HIV clinic in India: potential benefits of standardized national care delivery systems. $B M C$ Health Serv Res. 2011;11:277.

34. Siedner MJ, Santorino D, Lankowski AJ, et al. A combination SMS and transportation reimbursement intervention to improve HIV care following abnormal CD4 test results in rural Uganda: a prospective observational cohort study. BMC Med. 2015;13:160.

35. Munseri PJ, Talbot EA, Mtei L, et al. Completion of isoniazid preventive therapy among HIV-infected patients in Tanzania. Int J Tuberc Lung Dis. 2008;12:1037-1041.

36. Rosen S, Fox MP. Retention in HIV care between testing and treatment in sub-Saharan Africa: a systematic review. PLoS Med. 2011;8:e1001056.

37. Rosen S, Fox MP, Gill CJ. Patient retention in antiretroviral therapy programs in sub-Saharan Africa: a systematic review. PLoS Med. 2007;4:e298.

38. Brinkhof MW, Pujades-Rodriguez M, Egger M. Mortality of patients lost to follow-up in antiretroviral treatment programmes in resource-limited settings: systematic review and meta-analysis. PLoS One. 2009;4:e5790.

39. May M, Boulle A, Phiri S, et al. Prognosis of patients with HIV-1 infection starting antiretroviral therapy in sub-Saharan Africa: a collaborative analysis of scale-up programmes. Lancet. 2010;376:449-457.

40. Bezabhe WM, Chalmers L, Bereznicki LR, et al. Barriers and facilitators of adherence to antiretroviral drug therapy and retention in care among adult HIV-positive patients: a qualitative study from Ethiopia. PLoS One. 2014;9:e97353.

41. Patel S, Baxi RK, Patel SN, et al. Perceptions regarding barriers and facilitators to combination antiretroviral therapy adherence among people living with HIV/AIDS in Gujarat, India: a qualitative study. Indian J Sex Transm Dis. 2012;33:107-111.

42. Tuller DM, Bangsberg DR, Senkungu J, et al. Transportation costs impede sustained adherence and access to HAART in a clinic population in southwestern Uganda: a qualitative study. AIDS Behav. 2010;14:778-784.

43. Mills EJ, Nachega JB, Bangsberg DR, et al. Adherence to HAART: a systematic review of developed and developing nation patient-reported barriers and facilitators. PLoS Med. 2006;3:e438.

44. Bauman LJ, Braunstein S, Calderon Y, et al. Barriers and facilitators of linkage to HIV primary care in New York City. J Acquir Immune Defic Syndr. 2013;64(suppl 1):S20-S26.

45. Namusobya J, Semitala FC, Amanyire G, et al. High retention in care among HIV-infected patients entering care with CD4 levels $>350$ cells/ muL under routine program conditions in Uganda. Clin Infect Dis. 2013; $57: 1343-1350$

46. Kimeu M, Burmen B, Audi B, et al. The relationship between adherence to clinic appointments and year-one mortality for newly enrolled HIV infected patients at a regional referral hospital in Western Kenya, January 2011-December 2012. AIDS Care. 2016;28:409-15.

47. Glass TR, Sterne JA, Schneider MP, et al. Self-reported nonadherence to antiretroviral therapy as a predictor of viral failure and mortality. AIDS. 2015;29:2195-2200.

48. Ramirez-Avila L, Regan S, Giddy J, et al. Depressive symptoms and their impact on health-seeking behaviors in newly-diagnosed HIV-infected patients in Durban, South Africa. AIDS Behav. 2012;16: 2226-2235.

49. Battles HB, Wiener LS. From adolescence through young adulthood: psychosocial adjustment associated with long-term survival of HIV. $J$ Adolesc Health. 2002;30:161-168.

50. Murphy DA, Wilson CM, Durako SJ, et al. Antiretroviral medication adherence among the REACH HIV-infected adolescent cohort in the USA. AIDS Care. 2001;13:27-40.

51. Naar-King S, Templin T, Wright $\mathrm{K}$, et al. Psychosocial factors and medication adherence in HIV-positive youth. AIDS Patient Care and STDS. 2006;20:44-47.

52. Ironson $\mathrm{GH}, \mathrm{O}$ 'Cleirigh $\mathrm{C}$, Weiss $\mathrm{A}$, et al. Personality and HIV disease progression: role of NEO-PI-R openness, extraversion, and profiles of engagement. Psychosom Med. 2008;70:245-253.

53. Bianco JA, Heckman TG, Sutton M, et al. Predicting adherence to antiretroviral therapy in HIV-infected older adults: the moderating role of gender. AIDS Behav. 2011;15:1437-1446.

54. Nakimuli-Mpungu E, Bass JK, Alexandre P, et al. Depression, alcohol use and adherence to antiretroviral therapy in sub-Saharan Africa: a systematic review. AIDS Behav. 2012;16:2101-2118.

55. Mutumba M, Musiime V, Lepkwoski JM, et al. Examining the relationship between psychological distress and adherence to anti-retroviral therapy among Ugandan adolescents living with HIV. AIDS Care. 2016; 28:807-815.

56. Safren SA, Biello KB, Smeaton L, et al. Psychosocial predictors of nonadherence and treatment failure in a large scale multi-national trial of antiretroviral therapy for HIV: data from the ACTG A5175/PEARLS trial. PLoS One. 2014;9:e104178.

57. Bush B, Shaw S, Cleary P, et al. Screening for alcohol abuse using the CAGE questionnaire. Am J Med. 1987;82:231-235.

58. Englbrecht M, Alten R, Aringer M, et al. Validation of standardized questionnaires evaluating symptoms of depression in rheumatoid arthritis patients - approaches to screening for a frequent and yet underrated challenge. Arthritis Care Res (Hoboken). 2017;69: $58-66$.

59. Lowe B, Spitzer RL, Grafe K, et al. Comparative validity of three screening questionnaires for DSM-IV depressive disorders and physicians' diagnoses. $J$ Affect Disord. 2004;78:131-140. 